\title{
Prevalence and risk factors of gallstone disease in patients undergoing ultrasonography at Mulago hospital, Uganda
}

\author{
Stella Nimanya, William Ocen, Patson Makobore, Emmanuel Bua, Badru Ssekitooleko, Felix Oyania
}

Mulago National Referral Hospital.

\section{Author details:}

+256777007237 stellahalyce@gmail.com, +256772591557 ocenwilliam@yahoo.co.uk, +256 772378131 patsonmakobore@yahoo.com, +256703557471 emmanuelbua13@gmail.com; +256702965196 sbadru2050@gmail.com; +256774666222.oyafel@icloud.com

\begin{abstract}
Background: Gallstone disease (GSD) is the most prevalent medical condition in the pancreatobiliary system. The burden of GSD and its complications are major public health issues globally. It is a common cause of surgical intervention, contributing substantially to health care costs. Most patients are asymptomatic, however $20 \%$ become symptomatic after 10 years. Its prevalence differs among populations and remains unknown in Uganda.

Objective: To determine the prevalence and risk factors of GSD in patients undergoing abdominal ultrasonography at Mulago hospital, Uganda.

Methods: This was a cross-sectional study at the Department of Radiology in Mulago hospital. Convenient sampling was used to recruit individuals having an abdominal ultrasound scan. Questionnaires were used to assess risk factors, and an abdominal exam was performed for individuals with gallstones to assess symptomatology.

Results: The prevalence of GSD was $22 \%$. Statistically significant factors associated with GSD were a history of hormonal contraceptive use OR 3.2 (1.88-5.41) and a history of previous biliary symptoms OR 2.9 (1.68-4.91). Ninety-four percent of individuals with gallstones had epigastric/right upper quadrant pain.

Conclusion: The prevalence of GSD is high in Mulago hospital; use of hormonal contraceptives and a previous history of biliary symptoms were significant risk factors for GSD in this study. Majority of patients with GSD were symptomatic with epigastric pain as the cardinal symptom. We recommend a countrywide screening program using abdominal ultrasonography to determine the prevalence of GSD in the general population. There is need to study further the risk of hormonal contraceptive use and GSD. Women on these contraceptives should be informed of the potential risk, and offered alternative options where feasible.
\end{abstract}

Keywords: Gallstone disease, ultrasonography, Mulago hospital, Uganda.

DOI: https://dx.doi.org/10.4314/ahs.v20i1.44

Cite as: Nimanya S, Ocen W, Makobore P, Bua E, Ssekitooleko B, Oyania F. Prevalence and risk factors of gallstone disease in patients undergoing ultrasonography at Mulago hospital, Uganda. Afri Health Sci. 2020;20(1):383-91. https:/ / dx.doi.org/10.4314/abs.v20i1.44

\section{Introduction}

Gallstone disease (GSD) is still the most prevalent medical issue in the pancreatobiliary system ${ }^{1,2}$ and poses a myriad of challenges for health workers and patients alike. GSD is a worldwide problem and it remains a common

\section{Corresponding author: \\ Stella Nimanya, Mulago National Referral Hospital, Kampala Uganda. \\ Tel: +256777007237 \\ Email: stellahalyce@gmail.com}

cause of surgical intervention, contributing substantially to health care costs. Its prevalence however, varies widely among different populations. Among American adults the prevalence of gallstone disease is about $10 \%$ while in Western Europe the prevalence ranges from 5.9\% to $21.9 \%$ Prevalence rates of $3.2 \%$ to $15.6 \%$ have been reported from Asia ${ }^{3}$.

The burden of gallstone disease (GSD) and its complications, such as cholecystitis, pancreatitis, and cholangitis, are major public health issues globally ${ }^{4}$. About 1 million new patients annually are found to have gallstones, of which approximately 600,000 undergo cholecystectomy ${ }^{5}$. 
A 2006 study reported that more than 700,000 cholecystectomies were performed in the United States at a cost of $\$ 6.5$ billion dollars annually ${ }^{4}$. Most patients with GSD are asymptomatic, and approximately $20 \%$ become symptomatic after 10 years of follow-up ${ }^{6}$.

Although the mortality rate for GSD is relatively low at $0.6 \%$, the high burden of disease imposes troubling mortality figures, such as an estimated 1,092 gallstone-related deaths for 2004 in the U.S .

GSD has historically been considered rare in sub-Saharan Africa ${ }^{8,9}$. As many African countries undergo rapid urbanization with a steady shift towards a westernized diet, GSD will assume importance in these populations? Prevalence rates reported in African populations include $5.9 \%$ in Ghana, ${ }^{10} 5.2 \%$ in Sudan and Ethiopia ${ }^{11}$.

The current prevalence of GSD in Uganda remains speculative.

The objective of this study was to determine the prevalence, symptomatology and associated risk factors of GSD in patients undergoing abdominal ultrasound scan at MNRH, Uganda.

\section{Methods}

Approval was sought from the departments of Surgery and Radiology, Makerere University School of Medicine Ethics and Research Committee and the School of Graduate studies. Informed consent was obtained from the participants. Assent was obtained from children and written informed consent from children.

\section{Study design}

This was a cross-sectional study conducted at the Department of Radiology in Mulago National Referral Hospital. The study was conducted from January 2018 to April 2018.

\section{Study setting}

The study was conducted at the Department of Radiology in Mulago National Referral Hospital (MNRH), Kampala district. Mulago is Uganda's national referral hospital. The Radiology department provides ultrasonography and other imaging services. The ultrasound scan imaging modality is the second most common imaging modality in this department after general radiology ${ }^{12}$.

\section{Study participants}

All patients having an abdominal ultrasound scan at the
Radiology department during the study period were eligible for the study. Convenient sampling was used by the investigators to recruit study participants, and only those that consented were eligible for analysis. There was no exclusion criteria.

\section{Study variables}

Independent study variables included patient's age, sex, tribe, BMI, occupation, level of education, residence. The dependent variable was Gallstone disease. Intervening variables included diet, hormonal contraceptives, pregnancy, parity, diabetes, sickle cell disease.

\section{Data sources/measurement}

Patient information (demographics, past medical and surgical history, obstetric history, dietary habits and physical activity) was obtained and filled out on a data collection tool. Biliary symptoms were defined as dull colicky pain (episodic, steady) in the right upper part of the abdomen, which might radiate to the shoulder, lasting more than 30 minutes associated with nausea/vomiting.

Weight and height measurements were then obtained using a calibrated mechanical patient scale series SH-8024, with an attached height gauge after removal of shoes and heavy personal items on individuals and results recorded on the data collection tool. The measurements were used to calculate the BMI, and classified into underweight (BMI <18.5), normal (BMI >18.5 and <25), overweight $($ BMI $>25$ and $<30)$ and obese $($ BMI $>30)$.

Patient blood pressure was measured as a single reading using a Geratherm automatic blood pressure machine, with appropriate pediatric and adult cuffs attached to the left arm. In adults, a systolic greater than $140 \mathrm{mmHg}$ was categorized as a high systolic pressure, while a diastolic more than $90 \mathrm{mmHg}$ was defined as a high diastolic pressure. In children, the age specific percentile curves were used to determine the systolic and diastolic blood pressures. A normal blood pressure was defined as an average systolic and diastolic pressure less than the 90th percentile. A high blood pressure was defined as an average systolic and diastolic pressure above the $95^{\text {th }}$ percentile.

An abdominal ultrasound scan was performed by radiographers at the Radiology department using a trans-abdominal probe of the SIUI Apogee 5300 scan with the patients in the supine position. The gallbladder and biliary tree were assessed using a trans-abdominal ultra- 
sound scan probe. Gallstones on ultrasound were defined as presence of intraluminal, echogenic, mobile foci that were gravity dependent and created an acoustic shadow. Findings were recorded in thedata collection tool.

An abdominal examination was then performed on individuals that had ultrasonography confirmed gallstones to determine presence of epigastric/right upper abdominal quadrant tenderness and jaundice. An axillary temperature was measured, and a fever was defined as the presence of a temperature greater or equal to 37.5

The recruited research assistants were trained on the use of the data collection tool, how to perform the different measurements and patient approach. Five radiographers performed the ultrasound scans. In an attempt to reduce inter observer variability, their technique was standardized, by moving patients from the supine to the left lateral decubitus position and encouraging patients to take and hold a deep breath to aid improved visualization of the gallbladder.

\section{Sample size}

Using the Kish Leslie formula (1965): Where $n=z^{2} \times p$ $(1-p) / d^{2}$

$\mathrm{n}=$ required sample size;

$\mathrm{z}=$ standard error of the mean which corresponds to $95 \%$ confidence level (standard value of 1.96 );

$\mathrm{p}=$ There was no published study in Uganda on the prevalence of gallstone disease, we assumed a $50 \%$ prevalence to get the maximum sample size

$\mathrm{d}=$ margin of error at $5 \%$ (standard value of 0.05$)$ $\mathrm{n}=1.96^{2} \times 0.5(1-0.5) /(0.05)^{2}=385$ participants;

Accounting for $20 \%$ non-response rate the study required a minimum of 462 participants. However, we sampled all the 511 patients who were available during the study time.

\section{Statistical methods}

Data was first entered into a Microsoft Access database anddouble checked by the principal researcher before being exported to STATA version 12.0 software for analysis. The prevalence of gall stones was determined as a proportion. Logistic models were fit with each of the independent variables and presence of gall stones. Factors with $\mathrm{P}$ value less than or equal to 0.2 were entered into the multivariable model. The generalized linear model of the log binomial model was run using the variables that met the entry criteria for univariate analysis. The significant independent variables associated with gall stones in the model were used to form two-way product terms. The confounding effect of the different variables was assessed where appropriate by obtaining an odds ratio with the variable in the model and one without the variable. A confounder was considered as any variable that leads to $\geq 10 \%$ difference in the odds ratio. The $95 \%$ confidence intervals and P-values at two tailed level of significance were presented. The symptomatology was summarized as proportions.

\section{Results}

A total of 511 participants were consecutively recruited into the study from January 2018 to April 2018. 
Table 1: Socio demographic characteristics of study participants

\begin{tabular}{|c|c|c|c|}
\hline Characteristic & Category & Frequency & Percentage \\
\hline \multirow[t]{5}{*}{ Tribe $(\mathrm{n}=506)$} & Baganda & 270 & 53 \\
\hline & Banyakole/Mukiga & 106 & 21 \\
\hline & Acholi & 3 & 1 \\
\hline & Other Luo & 15 & 3 \\
\hline & Munyoro/mutoro & 112 & 22 \\
\hline \multicolumn{4}{|l|}{ Non-response (n=5) } \\
\hline \multirow[t]{2}{*}{$\operatorname{Sex}(\mathrm{n}=511)$} & Male & 178 & 35 \\
\hline & Female & 333 & 65 \\
\hline \multirow[t]{5}{*}{ Occupation $(\mathrm{n}=509)$} & None & 49 & 10 \\
\hline & Student & 109 & 21 \\
\hline & Peasant & 252 & 50 \\
\hline & Cooperate & 92 & 18 \\
\hline & Child & 7 & 1 \\
\hline \multicolumn{4}{|l|}{ Non-response $(\mathrm{n}=\mathbf{2})$} \\
\hline \multirow[t]{5}{*}{ Education level (n=511) } & None & 41 & 8 \\
\hline & Primary & 159 & 31 \\
\hline & Secondary & 151 & 30 \\
\hline & University & 66 & 13 \\
\hline & Tertiary & 94 & 18 \\
\hline \multirow[t]{7}{*}{ Age in years $(n=509)$} & $0-10$ & 18 & 4 \\
\hline & $11-20$ & 62 & 12 \\
\hline & $21-30$ & 126 & 25 \\
\hline & $31-40$ & 120 & 24 \\
\hline & $41-50$ & 72 & 14 \\
\hline & $51-60$ & 58 & 11 \\
\hline & $>60$ & 53 & 10 \\
\hline
\end{tabular}


Table 2: Medical History and behavioral characteristics of study participants

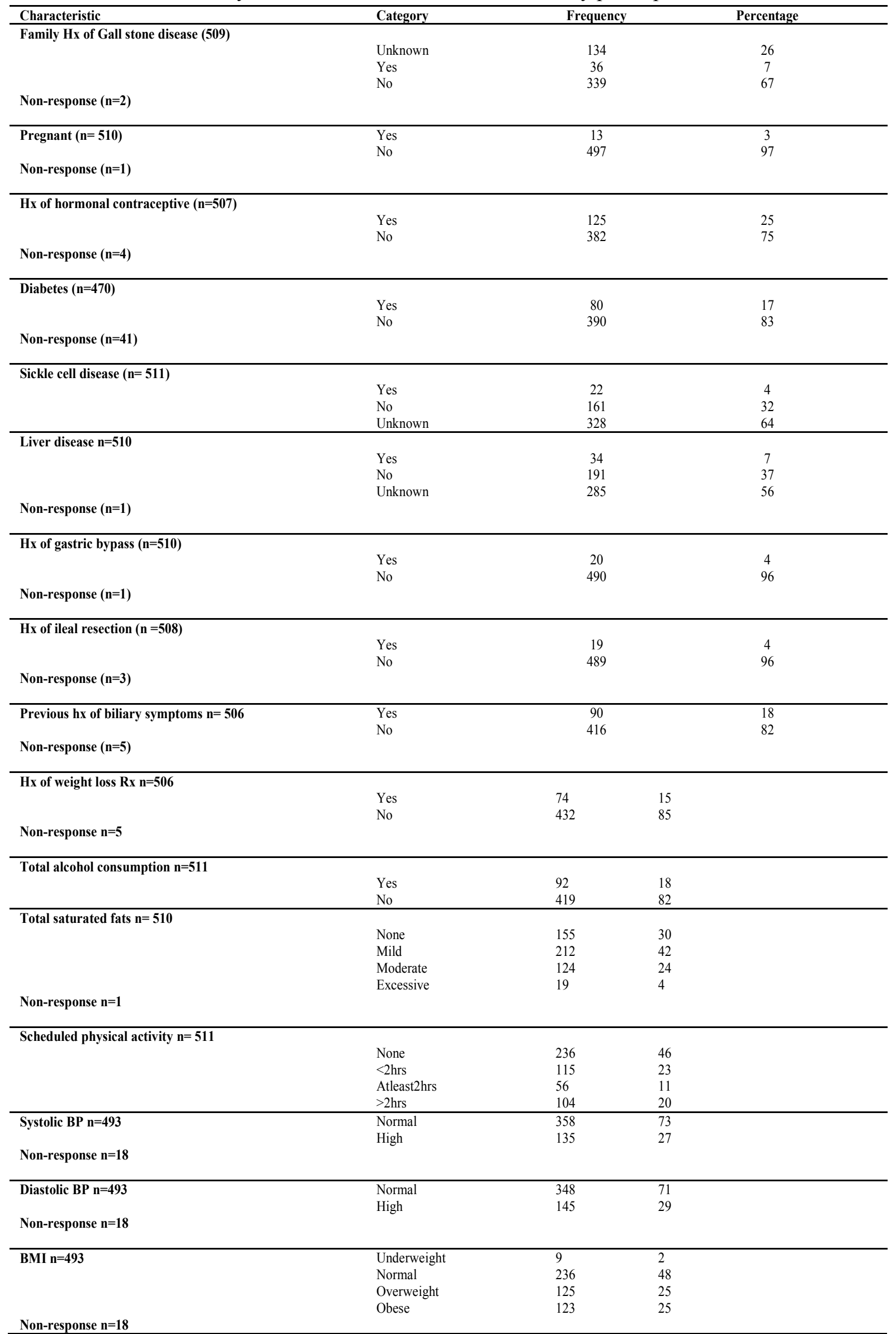




\section{Prevalence of Gall stones among study participants}

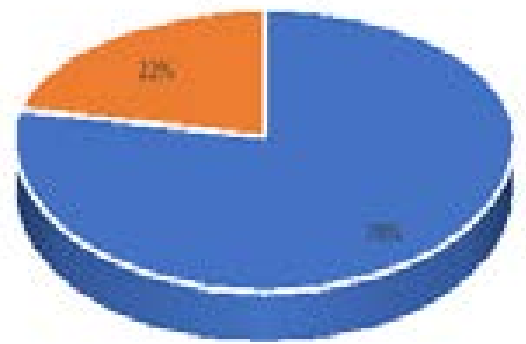

\section{- Galitenes Abscen ( $\mathrm{n}=396)$, Gdelstees Presert ( $\mathrm{n}=112$ )}

Figure 1: Prevalence of gall stones among study participants

Table 3: Univariate Analysis of the factors associated with Gall stones among study participants

\begin{tabular}{|c|c|c|c|c|}
\hline Characteristic & Category & Patients with GBS n (\%) & Odds Ratio [95\% CI] & P-value \\
\hline \multicolumn{5}{|l|}{ Sex } \\
\hline & Male & $37(33 \%)$ & 1 & \\
\hline & Female & $74(67 \%)$ & $1.1(0.70-1.70)$ & 0.704 \\
\hline \multicolumn{5}{|c|}{ Family history of GSD } \\
\hline & Unknown & $42(38 \%)$ & 1 & \\
\hline & & $11(10 \%)$ & $0.9(0.42-2.07)$ & 0.864 \\
\hline & no & $59(52 \%)$ & $0.4(0.28-0.71)$ & 0.001 \\
\hline \multicolumn{5}{|l|}{ Pregnant } \\
\hline & Yes & $3(3 \%)$ & 1 & \\
\hline & No & $108(97 \%)$ & $0.7(0.19-2.85)$ & 0.664 \\
\hline Parity (Co-eff) & & & $0.5(-0.01-0.12)($ Co-eff $)$ & 0.115 \\
\hline \multicolumn{5}{|c|}{ Hormonal contraception use } \\
\hline & No & $65(60 \%)$ & 1 & \\
\hline & Yes & $44(40 \%)$ & $2.7(1.72-4.27)$ & $<0.001$ \\
\hline \multicolumn{5}{|l|}{ Diabetes } \\
\hline & No & $87(80 \%)$ & 1 & \\
\hline & yes & $22(20 \%)$ & $1.3(0.76-2.26)$ & 0.335 \\
\hline \multicolumn{5}{|c|}{ Sickle cell disease } \\
\hline & No & $53(47 \%)$ & 1 & \\
\hline & & $10(9 \%)$ & $1.7(0.68-4.11)$ & 0.267 \\
\hline & Unknown & $49(44)$ & $0.4(0.23-0.55)$ & 0 \\
\hline \multicolumn{5}{|l|}{ Liver disease } \\
\hline & Yes & $11(10 \%)$ & 1 & \\
\hline & & $52(46 \%)$ & $0.8(0.36-1.74)$ & 0.564 \\
\hline & unknown & $49(44 \%)$ & $0.4(0.20-0.95)$ & 0.037 \\
\hline \multicolumn{5}{|c|}{ Gastric bypass history } \\
\hline & No & $109(97 \%)$ & 1 & \\
\hline & Yes & $3(3 \%)$ & $0.6(0.18-2.13)$ & 0.44 \\
\hline \multicolumn{5}{|c|}{ Ileal disease history } \\
\hline & No & $108(97 \%)$ & & \\
\hline & Yes & $3(3 \%)$ & $0.7(0.19-2.29)$ & 0.509 \\
\hline \multicolumn{5}{|l|}{ Sliming history } \\
\hline & No & $89(79 \%)$ & 1 & \\
\hline & Yes & $23(21 \%)$ & $1.7(1.00-2.97)$ & 0.05 \\
\hline \multicolumn{5}{|l|}{ Alcohol } \\
\hline & No & $81(72 \%)$ & 1 & \\
\hline & Yes & $31(28 \%)$ & $2.1(1.30-3.52)$ & 0.003 \\
\hline \multicolumn{5}{|c|}{ Saturated Fats consumption } \\
\hline & None & $39(35 \%)$ & 1 & \\
\hline & Mild & $41(37 \%)$ & $0.7(0.43-1.16)$ & 0.172 \\
\hline & Moderate & $28(25 \%)$ & $0.9(0.50-1.52)$ & 0.621 \\
\hline & Excessive & $4(3 \%)$ & $0.8(0.26-2.71)$ & 0.774 \\
\hline \multicolumn{5}{|c|}{ Scheduled physical activity } \\
\hline & None & $51(45 \%)$ & 1 & \\
\hline & $<2 \mathrm{hrs}$ & $34(30 \%)$ & $1.6(0.93-2.58)$ & 0.089 \\
\hline & Atleast $2 \mathrm{hrs}$ & $12(10 \%)$ & $1.0(0.48-2.00)$ & 0.964 \\
\hline & $>2 \mathrm{hrs}$ & $15(13 \%)$ & $0.6(0.32-1.14)$ & 0.121 \\
\hline \multicolumn{5}{|c|}{ History of biliary symptoms } \\
\hline & No & $74(67 \%)$ & 1 & \\
\hline & Yes & $37(33 \%)$ & $3.3(2.04-5.47)$ & $<0.001$ \\
\hline \multicolumn{5}{|l|}{ Age } \\
\hline & $1-10$ & $4(4 \%)$ & & \\
\hline & $11-20$ & $6(6 \%)$ & $0.4(0.09-1.51)$ & 0.168 \\
\hline & $21-30$ & $17(16 \%)$ & $0.6(0.16-1.89)$ & 0.347 \\
\hline & $31-40$ & $27(25 \%)$ & $1.0(0.31-3.38)$ & 0.965 \\
\hline & $41-50$ & $20(18 \%)$ & $1.4(0.40-4.68)$ & 0.613 \\
\hline & $51-60$ & $18(17 \%)$ & $1.6(0.45-5.46)$ & 0.474 \\
\hline & $>60$ & $17(16 \%)$ & $1.7(0.47-5.78)$ & 0.432 \\
\hline BMI & & & & \\
\hline & Underweight & $10(1 \%)$ & 1 & \\
\hline & Normal & $47(46 \%)$ & $0.8(0.47-1.33)$ & 0.377 \\
\hline & Overweight & $26(25 \%)$ & $0.8(0.46-1.54)$ & 0.574 \\
\hline & Obese & $29(28 \%)$ & 1.0 & \\
\hline
\end{tabular}


Table 4: Multivariate analysis of the factors associated with Gall stones among study participants

\begin{tabular}{llll}
\hline Characteristic & Odds Ratio & $\mathbf{( 9 5 \%} \mathbf{C I})$ & P-value \\
\hline Hormonal contraception & 1 & & \\
No & 3.2 & $1.88-5.41$ & $\mathbf{0 . 0 0 0 1}$ \\
Yes & 1 & & \\
\hline History of slimming & 1.2 & $0.65-2.22$ & 0.556 \\
No & & & \\
Yes & 1 & & \\
\hline Alcohol consumption & 1.6 & $0.90-2.85$ & \\
No & & & \\
Yes & 1 & & \\
\hline History of Biliary symptoms & 2.9 & $1.68-4.91$ & \\
No & & & \\
yes & 1.0 & & \\
\hline Age & 0.3 & 0.0001 \\
$1-10.0$ & 0.3 & $0.09-1.14$ & 0.079 \\
$11.0-20$ & 0.4 & $0.12-1.48$ & 0.176 \\
$21-30$ & 0.7 & $0.20-2.65$ & 0.639 \\
$31-40$ & 1.1 & $0.31-4.06$ & 0.852 \\
$41-50$ & 1.1 & $0.31-4.19$ & 0.835 \\
$51-60$ & & & \\
$>60$ & & & \\
\hline
\end{tabular}

At multivariate analysis, participants who had used hormonal contraception were likely to have gall bladder stones. A history of biliary symptoms was also significant in patients with gall stones.

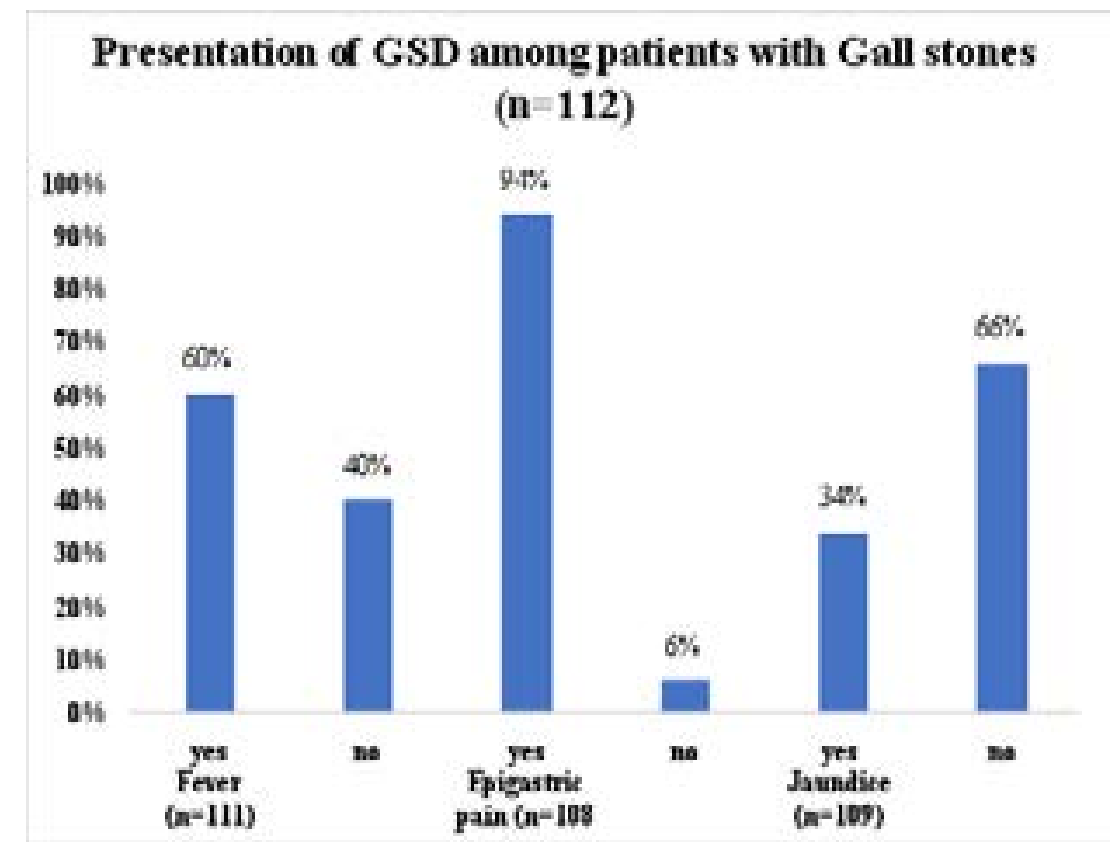

Figure 2: Presentation of GSD among patients with Gall stones

$33 \%$ of the patients with gallstones had all three symptoms present at the time of ultrasonography. $65 \%$ had either one or 2 symptoms. Only $6 \%$ had no symptoms at all.

\section{Discussion}

There were $331(65 \%)$ females and $177(35 \%)$ males recruited in this study. This could be due to the fact that females are more likely than males to have an abdominal ultrasound scan performed during their health assessment, andthat females have better health seeking behavior in comparison to males ${ }^{13}$.

\section{Prevalence of gallstone disease}

The overall prevalence of gall stones in our study was $22 \%$. This finding is much higher than the $5.9 \%$ prevalence in Ghana ${ }^{10}$, and $5.2 \%$ in Ethiopia ${ }^{11}$. This could be attributed togenetic differences, dietary differences, as well as differences in levels of activity, with Ugandans having less physical activity ${ }^{14}$. It is comparable to $22.8 \%$ 
in the Uighur Chinese population ${ }^{15}$ However it is less than the $39.1 \%$ over 3 years and $60.9 \%$ over 5 years in a Nigerian study ${ }^{9}, 70 \%$ in Pima Indians ${ }^{4}$ and the $72.2 \%$ among British adults ${ }^{16}$. This could be explained bythe fact that these were population based studies, carried out over longer periods of time as opposed to our study population, which was limited to one hospital.

\section{Factors associated with gallstone disease}

The study findings indicated that women who had used hormonal contraceptives were three times more likely to have gall stones OR 3.2 (1.88-5.41). According to the Uganda Demographic Health survey, injectable (hormonal) contraceptives are the most used method of family planning by Ugandan women. Several studies done have shown that the risk of GSD is higher in females than in males $^{3}$ with the difference being attributed to female sex hormones, parity and hormonal contraception use. In our study, although gender was not statistically significant, females had slightly higher odds of GSD as compared to males. GSD is the major non-obstetric cause for hospitalization in the first year postpartum ${ }^{17}$ however, pregnancy was not a significant risk factor in our study. This could be a result of the small numbers of pregnant women sampled in our study, as pregnant women were more likely to have their routine ultrasound scans done in the antenatal unit, as opposed to the radiology department. Parity was also not statistically significant in our study. Several other studies have also failed to demonstrate parity and pregnancy as risk factors of $\mathrm{GSD}^{18,19}$.

Study findings indicated that patients with a previous history of biliary symptoms (biliary colic with associated nausea/vomiting) were more likely to have gall stones OR 2.9. This was in line with the high proportion of individuals in our study with GSD presenting with epigastric pain. This finding could explain why several patients with GSD in our setting are initially treated for peptic ulcer disease for a long period of time before the GSD diagnosis is eventually made following imaging.

Study participants with a history of alcohol consumption had higher odds of having GSD as compared to those without, even though alcohol intake was not statistically significant for GSD.

History of use of weight loss regimens was associated with greater odds of having GSD (OR 1.2), but was not statistically significant in this study. A history of dieting has been identified as a risk factor for gallstone formation $^{20}$.

\section{Symptomatology of gallstone disease}

Majority of patients in our study were symptomatic with epigastric pain accounting for the highest symptom, followed by fever and jaundice respectively. A combination of all three symptoms was present in $29 \%$ of the patients with GSD. Only $6 \%$ of the patients with gallstones in our study did not have any symptoms at presentation This is contrary to several studies that suggest majority of gallstone patients remain asymptomatic, even though approximately $20 \%$ of these become symptomatic after 10 years of follow up ${ }^{6}$. The high proportion of symptomatic patients in our study could be explained by the fact that it was a hospital based study as opposed to a population based study. A study by Jorgensen ${ }^{21}$ concluded that in a random population it is difficult to define the symptoms specific for gallstones and thereby distinguish between symptomatic and asymptomatic gallstones.

\section{Study limitations}

Diabetes, family history of GSD, sickle cell and liver disease were assessed through history rather than by laboratory examination. . Patients did not fast over night before the abdominal ultrasound scans were performed. Abdominal ultrasonography was performed by different radiographers thus conveying a degree of inter observer bias. We attempted to control for this bias by standardizing the technique with which the scan was performed.

\section{Conclusion}

The prevalence of gallstone disease is high among patients presenting for routine abdominal USS at MNRH. A history of hormonal contraceptive use is a significant risk factor for GSD. Individuals with a previous history of biliary symptoms have a higher likelihood of GSD. Majority of the patients with GSD had symptoms at presentation for the abdominal ultrasound scan.

We recommend, a screening program using abdominal ultrasonography should be implemented countrywide. This will provide information on the burden of GSD in the Ugandan population, as well as aid early detection and management of the disease.

Further studies should be carried out to ascertain hormonal contraceptive use as a risk factor for GSD in the 
general Ugandan population. Women using these contraceptives should be informed of this possible risk, and offered alternatives where feasible, especially in those already predisposed to GSD by having other documented non-modifiable risk factors such sickle cell disease.

\section{Abbreviations}

$\begin{array}{ll}\text { BMI } & \text { Body Mass Index } \\ \text { GSD } & \text { Gallstone disease } \\ \text { Hx } & \text { History } \\ \text { MNRH } & \text { Mulago National Referral Hospital } \\ \text { OR } & \text { Odds Ratio } \\ \text { RUQ } & \text { Right Upper abdominal Quadrant } \\ \text { USS } & \text { Ultrasound scan }\end{array}$

\section{Conflict of interest}

None declared.

\section{References}

1. Chang YR, Jang JY, Kwon W, Park JW, Kang MJ, Ryu $\mathrm{JK}$, et al. Changes in demographic features of gallstone disease: 30 years of surgically treated patients. Gut and Liver. 2013;7(6):719-24.

2. Portincasa P, Moschetta A, Palasciano G. Cholesterol gallstone disease. Lancet (London, England). 2006;368(9531):230-9.

3. Shaffer EA. Epidemiology and risk factors for gallstone disease: has the paradigm changed in the 21st century? Current Gastroenterology Reports. 2005;7(2):132-40.

4. Shaffer EA. Gallstone disease: Epidemiology of gallbladder stone disease. Best Practice \& Research Clinical Gastroenterology. 2006;20(6):981-96.

5. NIH Consensus conference. Gallstones and laparoscopic cholecystectomy. JAMA. 1993;269(8):1018-24.

6. Attili AF, De Santis A, Capri R, Repice AM, Maselli S. The natural history of gallstones: the GREPCO experience. The GREPCO Group. Hepatology (Baltimore, Md). 1995;21(3):655-60.

7. Everhart JE, Ruhl CE. Burden of digestive diseases in the United States Part III: Liver, biliary tract, and pancreas. Gastroenterology. 2009;136(4):1134-44.

8. Perissat J. Laparoscopic surgery: A pioneer's point of view. World Journal of Surgery. 1999;23(8):863-8.

9. Rahman GA. Cholelithiasis and cholecystitis: changing prevalence in an African community. Journal of the National Medical Association. 2005;97(11):1534-8.
10. Gyedu A, Adae-Aboagye K, Badu-Peprah A. Prevalence of cholelithiasis among persons undergoing abdominal ultrasound at the Komfo Anokye Teaching Hospital, Kumasi, Ghana. African Health Sciences. 2015;15(1):246-52. 11. Getachew A. Epidemiology of gallstone disease in Gondar University Hospital, as seen in the department of radiology. Ethiop J Health Dev 2008;22(2):206-11.

12. Kawooya MG, Pariyo G, Malwadde EK, Byanyima $\mathrm{R}$, Kisembo $\mathrm{H}$. Assessing the performance of imaging health systems in five selected hospitals in Uganda. Journal of Clinical Imaging Science. 2012;2:12.

13. Thompson AE, Anisimowicz Y, Miedema B, Hogg W, Wodchis WP, Aubrey-Bassler K. The influence of gender and other patient characteristics on health care-seeking behaviour: a QUALICOPC study. BMC Family Practice. 2016;17:38.

14. Kirunda BE, Wamani H, Fadnes LT, Van den Broeck J, Tylleskar T. Objectively Assessed Physical Activity and Associated Factors Among Adults in Peri-Urban and Rural Eastern Uganda: A Population-based Study. Journal of Physical Activity \& Health. 2016;13(11):1243-54.

15. Zhu L, Aili A, Zhang C, Saiding A, Abudureyimu $\mathrm{K}$. Prevalence of and risk factors for gallstones in Uighur and Han Chinese. World Journal of Gastroenterology. 2014;20(40):14942-9.

16. Everhart JE, Khare M, Hill M, Maurer KR. Prevalence and ethnic differences in gallbladder disease in the United States. Gastroenterology. 1999;117(3):632-9.

17. Ko CW. Risk factors for gallstone-related hospitalization during pregnancy and the postpartum. The American Journal of Gastroenterology. 2006;101(10):2263-8.

18. Caroli-Bosc FX, Deveau C, Harris A, Delabre B, Peten EP, Hastier P, et al. Prevalence of cholelithiasis: results of an epidemiologic investigation in Vidauban, southeast France. General Practitioner's Group of Vidauban. Digestive Diseases and Sciences. 1999;44(7):1322-9.

19. Walcher T, Haenle MM, Kron M, Hay B, Mason RA, von Schmiesing AF, et al. Pregnancy is not a risk factor for gallstone disease: results of a randomly selected population sample. World Journal of Gastroenterology. 2005;11(43):6800-6.

20. Jorgensen T, Jorgensen LM. Gallstones and diet in a Danish population. Scandinavian Journal of Gastroenterology. 1989;24(7):821-6.

21. Jorgensen T. Abdominal symptoms and gallstone disease: an epidemiological investigation. Hepatology (Baltimore, Md). 1989;9(6):856-60. 